\title{
Nurturing bilingual learners: challenges and concerns in Singapore
}

Article

Accepted Version

Curdt-Christiansen, X.-L. and Sun, B. (2016) Nurturing

bilingual learners: challenges and concerns in Singapore. International Journal of Bilingual Education and Bilingualism, 19 (6). pp. 689-705. ISSN 1367-0050 doi:

https://doi.org/10.1080/13670050.2016.1181606 Available at https://centaur.reading.ac.uk/65684/

It is advisable to refer to the publisher's version if you intend to cite from the work. See Guidance on citing.

To link to this article DOI: http://dx.doi.org/10.1080/13670050.2016.1181606

Publisher: Routledge

All outputs in CentAUR are protected by Intellectual Property Rights law, including copyright law. Copyright and IPR is retained by the creators or other copyright holders. Terms and conditions for use of this material are defined in the End User Agreement.

\section{www.reading.ac.uk/centaur}

\section{CentAUR}

Central Archive at the University of Reading 
Reading's research outputs online 


\title{
Nurturing bilingual learners: Challenges and Concerns in Singapore
}

\author{
Xiao Lan CURDT-CHRISTIANSEN \\ Associate Professor \\ Institute of Education, University of Reading \\ 4 Redlands Road, Reading, Berkshire \\ RG1 5EX \\ UK \\ x.l.curdt-christiansen@ reading.ac.uk
}

\author{
Baoqi SUN \\ PhD \\ National Institute of Education, Nanyang Technological University \\ 4 JALAN LEMPENG \#05-01 PARK WEST \\ Singapore 128794 \\ sunbaoqi@ hotmail.com
}

\begin{abstract}
Singapore's bilingual policy legitimizes English not only as the language of governmental administration and interethnic communication, but also as the medium of instruction in all schools on all levels and across all subjects except mother tongues. As a result of these politics of language recognition, a visible shift has occurred in all ethnic groups away from mother tongues towards English. To rectify the language shift situation, the government has emphasized that developing bilingualism and raising bilingual children should begin in pre-schools. In this paper, we examine two top-down official documents: Review of Mother Tongue Languages Report, issued in 2011, and Nurturing Early Learners Framework for Mother Tongue Languages, developed in 2013. Attempting to identify some of the complex factors that influence language shift, we present an intertextual analysis of the Report and the curriculum Framework. In doing so, we compare the consistencies and locate the implicit inconsistencies in the policy position on bilingual education in preschools. We conclude the article by outlining the implications for changing the current bilingual educational models and providing teacher training programmes that maximize the learning opportunities of young bilingual learners.
\end{abstract}

Key words: preschool, bilingual policy, curriculum framework, mother tongue languages, Singapore 


\section{Nurturing bilingual learners: Challenges and Concerns in Singapore}

\section{Introduction}

Singapore is inhabited by a population of 5.08 million (Statistics Singapore 2010), divided into three major ethnic groups - Chinese (76\%), Malays (13\%), and Indians (8\%). As an ethnically and linguistically diverse country, Singapore is well known for its bilingual language policy, which prescribes "English plus one of the official ethnic mother tongues" (MOE, 2012, p.1). Arguably, this policy has created a generation of 'English-knowing' bilinguals (Pakir, 2008) who are able to use English and the official mother tongues (MTs) ${ }^{1}$. It has, however, also engendered a visible language shift from MTs towards English in recent years (CurdtChristiansen, 2014b, 2016; Li, Saravanna \& Ng, 1997; Zhao \& Liu, 2008). Despite the government's deep concerns about MT displacement against the increasing formal and informal functions of English in almost all domains, the language shift phenomenon is continuously growing. In response, the government has initiated a series of educational innovations and curriculum reforms in order to reverse the trend, but the decline of MT competence among Singaporean children continues (Zhao \& Zhang, 2014). What is the fundamental issue underlying the language shift phenomenon? How can the phenomenon be reversed? What needs to be done at the educational and curriculum policy levels? What can be done to change people's attitudes towards MTs when work places and schools have high demands on English proficiency? From a language planning perspective, what status planning activities can be employed to enhance the functions of MTs and confirm their cultural values?

\footnotetext{
${ }^{1}$ Singaporeans speak a multitude of language varieties. The Chinese community has 11 dialects, including Hokkien, Teochew, and Cantonese; the Malays speak Bahasa Malaysia, Bugis and Javanese; the Indians use Punjabi, Urdu and Malayalam. These language varieties are not taught in schools as MTs because of the large number of different varieties of MTs. Discussion of these varieties as MT is beyond the scope of this paper.
} 
This paper addresses one of the curriculum reforms for preschools and examines two related documents, both by Ministry of Education (MOE) - the Review of MTLs Report (hereafter the Report ) from 2011 and the Nurturing Early Learners (NEL) Framework for Mother Tongue Languages (MTL) (hereafter the Framework) from 2013 and. In order to understand some factors that influence language shift, we provide an intertextual analysis of the Report and the Framework and compare the consistencies and inconsistencies with regard to the instructional guidelines and learning objectives. In doing so, we aim to locate the implicit inconsistencies in the policy positions on bilingual education in preschools.

\section{Bilingual Education: Curriculum Review and Language Ideology}

Bilingual education encompasses a variety of types and forms, based on the purposes and aims of language outcomes, from transitional models to maintenance and enrichment models (Baker, 2006). These include immersion programmes, heritage language programmes, and dual language programmes. While some of the programmes have a clear goal of achieving biliteracy and bilingualism, they may lack appropriate curricula to provide learning activities that are intellectually challenging and linguistically rich. Thus, evaluation of a curriculum should be regularly conducted to enhance the programme design and curriculum contents and eliminate conspicuous ideological intentions that can cause educational confusion.

\section{Curriculum Evaluation}

In a recent special issue on curriculum evaluation of early immersion programmes, Hickey and de Mejia (2014) examined some of the key issues and concerns related to policy implementation, teacher training programmes and learning outcomes in different political contexts. Their evaluation revealed that political decisions on what language to teach and how much exposure children should have to target languages in early years tend to be related to 
language status and the language rights of specific communities in multilingual societies. In the context of Acadian French in Canada (Cormier, Bourque \& Jolicoeur, 2014), Gaelic in Ireland and Welsh in Wales (Hickey, 2001; Hickey, Lewis \& Baker, 2014), curriculum implementation is intended to revitalise the endangered heritage language of the Francophone and Celtic minorities. In the context of Belgium (Buyl \& Housen, 2014), however, the immersion programme is not targeted at one of the national languages but at English because of its international dominance, as EU's multilingual policy emphasises that mother tongue plus two should be the norm in school education (Nikolov, 2010; Dendrinnos, 2014). While these policy decisions are based on convincing ideologies and supported by teachers and linguistic communities, how to enact the policies successfully depends largely on proper institutional guidance and on what teachers do in classrooms.

In the study of English immersion preschools in Belgian Francophone communities, Buyl and Housen (2014, p. 181) reported that there are few "specific official educational approaches or pedagogical principles for immersion teaching" in pre-service teacher training. Teachers were observed to develop their own teaching materials, designed for native speakers or other immersion contexts, which were not always appropriate for the local context. There are considerable variations in pedagogical principles and practices because of lack of official educational approaches to immersion teaching training. As a result, many teachers in the study "considered themselves insufficiently prepared or qualified to teach in immersion schools" (p. $181)$.

Similarly, Hickey et al. (2014) studied educators' skills and approaches to developing young Welsh learners' target language in Welsh-medium preschool nursery groups. They found that educators tend to provide insufficient target language input for the learners as they were 
concerned about the cognitive burden imposed on the young learners and about children's ability to understand instructions if only Welsh was used. These studies raise issues of adequacy of pedagogical training for immersion educators with regard to linguistic models and enrichment activities, suitable for developing bilingualism and biliteracy.

Immersion models and curriculum content are determining factors for bilingual learners' outcomes. Cormier et al. (2014) studied four different, early-immersion models for French (francisation) in Canada for francophone heritage learners where intergenerational transmission of French had ceased because of socio-historico-political development. The francisation immersion models included sheltered class, mainstream pull-out, in-class support and integrated programmes. Of these models, the integrated model produced the best learner outcome regarding children's French performance. In this integrated model, teachers not only used language focused teaching for students with similar French proficiencies, but also designed curriculum for heterogeneous groups where subject contents were integrated with language activities. No significant differences between the other three models were reported.

Lindholm-Leary's (2014) study focused on a dual language programme, involving English (the dominant language) and Spanish (a less prestigious language). The participants in her study were children of low socio-economic status (SES) from Spanish (L1) speaking background. Comparing Hispanic children of low SES who attended either bilingual preschool or English-only preschool, she found that children from both programmes performed progressively well in their English language and literacy skills over the course of three years. But by the third year (grade 1), the children in the dual-language programme performed significantly better in Spanish than their peers in the English-only programme, while there was little difference between the groups regarding their English language skills. These learner outcomes 
reflect that the programme not only was carried out in a supporting academic environment and had a vigorous curriculum with rich text literacy, it also had devoted teachers who had received training to implement various strategies to deal with the children's needs. Her study illustrates that children's L1 development in the bilingual programme did not present obstacles for their L2 learning. The success of the programme depended on devoted teachers and a vigorous text-rich literacy curriculum.

Examining a recent mother tongue curriculum review in Singapore, Zhao and Liu (2007; 2010) point out that, although the review has revealed the declining proficiency in mother tongue languages, the recommendations for the reform do not address the underlying issues. On the contrary, the recommendations have a negative effect on mother tongue language literacy because the reform has diluted the content of the MTL curriculum (Curdt-Christiansen, 2014b). Instead of enriching the curriculum by increasing the quantity and quality of language input (teaching hours) in mother tongues, the reform has simplified the language curriculum. Scholars (Curdt-Christiansen, 2014 a, 2014b; Li, Saravanna \& Ng, 1997; Zhao \& Liu, 2007; 2010) have argued that there are conflicting ideologies behind the language policy in Singapore which can make it difficult for schools to offer a consistent language education curriculum for bilingual development.

\section{Language Ideology}

Language ideology is a critical element in effective bilingual education as it reflects the socio-historical role, value, and function of a language or language variety in a given society (Blommaert, 2006; Woolard, 1998). How teachers and parents perceive a language is directly related to the power, value, status and utility of that language, thus divulging their attitudes towards and beliefs about a certain language (Baker, 1992; Curdt-Christiansen, 2009; Santello, 
2015). Within a given society, there are or can be many ideologies which agree or disagree with each other. In her study of bilingual families in Singapore, Curdt-Christiansen (2016) found that conflicting ideologies and contradictory practices are at work within the same families with regard to the upbringing of bilingual children. While the parents in her study expressed clearly positive views on MTs, their concerns about children's educational achievement, inflicted by the bilingual policy, had made them deliberately or unintentionally choose English in their everyday linguistic practices. Similar conflicts have also been identified in indigenous language revitalisation context (King, 2000; McCarty, 2011; ÓhIfearnáin, 2013). King's (2000) study of Ecuadorian parents illuminates the inconsistencies between community members' stated explicit 'pro-Indigenous' ideology and their privately held implicit 'anti-Indigenous' language ideology.

As a result, the revitalisation bilingual programme has not been effective and is therefore leading to community language shift.

In sum, any successful implementation of bilingual programmes requires a cohesive policy, clear goals, shared visions and interactions among policy makers, parents and teachers as well as consistency and continuity in curriculum provision. In the following section, we provide the contextual understanding of Singapore's educational system and situate the NEL Framework in the early bilingual programmes in Singaporean kindergartens.

\section{Education System in Singapore}

\section{Preschool}

In Singapore compulsory education begins with the first year of primary school, which is at age 7 (MOE, 2000). Preschool education encompasses child care centres and kindergartens. The former are licensed by the Ministry of Social and Family Development (MSF) and provides care and education for children from as young as two months and up until school age. The latter are 
registered with the Ministry of Education (MOE) and offers education for children aged 4-6 years: Nursery (4-year old), Kindergarten 1 (K1) (5-year old), and Kindergarten 2 (K2) (6-year old). For the purpose of consistency, we use the term 'preschool' here to cover bilingual programmes in both child care centres and kindergartens. Operators of preschools include a varied range: government subsidised anchor kindergartens or child care centres with affordable fees (e.g., the MOE kindergarten), private fee-charging kindergartens or child care centres, and non-profit organisation kindergartens or child care centres with moderate fees, established by ethnic communities or religious organisations.

Within these three major categories, schools can select their own curriculum content with regard to the number of hours allocated to English and mother tongue languages, as well as the activities related to the languages. Because MOE does not provide detailed guidance and syllabus, there are considerable variations in pedagogies, teaching materials and resources used by schools and teachers. Some of the materials for mother tongue languages are imported directly from native-speaking countries, such as Chinese story-books published in mainland China.

In 2011, MOE and MSF set up the Preschool Qualification Accreditation Committee (PQAC) to oversee the standard and quality of preschool teacher training for both kindergarten and child care sectors in Singapore (MOE, 2008). Since then, the entry qualifications for preschool teachers have been revised regularly. According to MOE's Pre-School Accreditation Framework (MOE, 2008), all preschool teachers are required to complete a training programme in order to obtain the Certificate in Early Childhood Care and Education (CECCE), and 25\% of the preschool teachers are trained at the Diploma in Early Childhood Care and Education Teaching (DECCE-T) level. In order to teach at the K1 and K2 levels, the existing teachers must 
have 'O' level credit (equivalent to a 9-year secondary education) in English Language (EL) / 5.5 in IELTS and DECCE-T. The same requirement applies to Mother Tongue Language (MTL) teachers, except that they will have to obtain a credit in MTL instead of in EL.

Preschool education in Singapore is a mélange of maintenance and enrichment type with various types of immersion and dual language programmes. Children come from different family language backgrounds and speak their two official languages with varied language proficiencies (Curdt-Christianen \& Silver, 2013; Vaish, 2007; Zhao \& Zhang, 2014).

With regard to curriculum activities, preschools' timetables echo those of primary schools where each teaching session lasts 30 minutes. Languages (English and MTs), numeracy, arts, music, and motor skills take up about equal portions of teaching time. It should be noted, however, that MT is used only during MT class, and English is used for all the remaining classes. The echo of the primary school curriculum not only prepares children for the transition from home to school, but also teaches them more than just basic literacy. This gives them a head-start in primary 1 and provides them with competitive academic skills of great help during processes of academic selection.

\section{Bilingual Education System in Singapore}

While the Singaporean government may proudly claim that "bilingual education is a cornerstone of Singapore's education system" (MOE, 2015), school curricula and contents of teaching do not reflect any of the strong forms of bilingual models as defined by Baker (2011). In Singaporean schools, MT is typically taught as a subject for 2-4 hours weekly, while English is both taught as a subject and used as the medium of instruction for content teaching of all subjects, which amounts to 4-5 hours daily. 
A feature of Singapore's educational system is the heavy emphasis on academic performance, where English, MT and Mathematics are the subjects of primary education exams. This emphasis expresses itself in the way children from an early age are prepared for academic excellence. The exam-oriented education system has impelled many kindergartens to advertise their curriculum as unique, in that they offer vigorous bilingual programmes and prepare children not only for primary 1 , but also for other academic challenges, such as critical and analytical tasks. Using their bilingual programme as a selling point, some preschools stress that they have both English and MT teachers in each classroom throughout the day. One of the most popular private preschools, Eton House, for example, states that they provide "a dual language environment and include one expatriate (native English-speaker) and one Mandarin speaking teacher in the classroom at all times" (Eton House, n.d.). Although some preschools market their programmes as 'authentic' bilingual immersion programmes with equal emphasis on Mandarin and English, they tend to have English as the language of instruction with stand-alone Chinese lessons (Murugayyan, 2011). Many of the programmes mimic what the primary schools offer, with structured systematic courses in English, emphasizing phonic skills, whole word recognition, development of reading and spelling, reading and comprehension, and even creative writing. MT lessons (e.g. Mandarin) are also structured, and children are exposed to frequent written exercises. In sum, much of the language curriculum puts emphasis on formal literacy skills, less on communicative skills and socio-emotional development.

Another characteristic of Singaporean education is the emphasis on English. Singapore's bilingual policy is characterised by official language management throughout the educational system, where English is the language of instruction for all subjects in all schools. Although the primary school curriculum gives 'equal' emphasis on subjects - English language, mother tongue, 
mathematics, and science (Primary 3 onwards), the demand for English proficiency is high as it directly affects children's academic performance. As a result, the emphasis on English has led to a gradual but significant shift to English where the social and communicative aspects of intergenerational transmission in MTs are slowly lost (Curdt-Christiansen, 2014b; Vaish, 2007; Zhao \& Liu, 2007; Zhao \& Zhang, 2014). Consequently, the social functions of MT have gradually lost battle ground to English. In school context, this is reflected by the decline in both communicative ability and literacy skills in MTs.

In response to these linguistic and social changes, MOE has revised the MT syllabus several times for both the primary and secondary levels to accommodate the needs of pupils from English-speaking families. At the preschool level, the MOE has set up the ECDA (Early Childhood Development Agency) to oversee all aspects of language education in kindergartens and child care centres. Concomitantly, the Report was published in 2011 and the Framework for MTs in 2013.

\section{Methods}

\section{Data Source - the Report and Framework}

Nurturing active learners and proficient users: 2010 mother tongue languages review committee report. In response to the changing linguistic landscape in Singapore, the MTL Review Committee was set up in 2010 to recommend appropriate strategies to enhance the teaching and learning of MTs. Based on extensive consultation with various stakeholders (teachers, students, parents) and in-depth discussion with different parties (language professionals, individuals, media professionals, and community leaders), the committee released its 115-page long report. Comprising eight chapters, it aims to ensure that the bilingual policy stays effective and relevant with the changing language environment. 
Nurturing Early Learners (NEL): A Framework for MTLs. As an effort to raise the quality of preschool education and guide the teaching and learning of MTs, the national kindergarten framework - Nurturing Early Learners (NEL) was introduced by in 2013. Based on the Report and consultations with local and overseas language experts and teachers, a 67-paged curriculum framework was published, consisting of four chapters and aiming to provide a common understanding across the sector of the principles, practices and outcomes for preschool education. According to the MOE, it serves as a guide to the teaching and learning of the three official MTLs in Singapore across the preschool sector.

We chose the Report and the Framework as our data source for several reasons: (1) the Report provides facts of the current MT situation in Singapore; 2) both documents attempt to identify the factors contributing to the decline of MTs; 3) both documents claim to provide counter measures to improve MTs in education. In essence, the two policies play a significant role in Singapore's bilingual education as they not only reflect the ideological positioning of educational and curriculum policies, but also provide guiding principles and practical knowledge for running a successful bilingual education programme. Studying the Report and Framework will allow us to see how these documents reflect and construct the linguistic and educational contexts which are associated with socio-historically, politically, economically and culturally defined practices in Singapore. As we set out to understand the language shift phenomenon, our theoretical positioning guides us to scrutinise how the two official documents are manifested in multiple layers of interactive context (Wodak \& Meyer, 2009). As such, the analysis provides much needed information to understand curriculum contents and activities that define the outcomes of bilingual education in Singapore.

\section{Data Analysis}


Level of analysis. Our data analysis method is guided by critical approaches to discourse analysis (Blomaert, 2005; Fairclough, 2001; Gee, 2005; Rogers, 2011). These approaches emphasise the uncovering of explicit and implicit meanings in any given text and provide means for understanding the relationship between texts and social contexts. Of particular relevance to this study is the concept of intertextuality (Fairclough, 2001; Lemke, 1992), which refers to the relationality and interconnectedness of text production with the broader socio-political and historical context.

Although intertextuality often refers to texts as multi-voiced or containing textual fragments of other texts, we use it to understand and trace the political and historical development of the linguistic environment. Our focus is on the extra-textual relations where we aim to describe and identify the ideological implications of the texts. Adopting Lemke's (1992) framework, we focus on three intertextual relations: 1) thematic, 2) orientational, and 3) organizational. The thematic intertextual relationship examines the topics of the two documents with the aim to identify the common grounds for constructing the documents. The orientational intertextual relations are based on texts/discourses that have similar ideological orientation. The organizational intertextual relations look at the patterns of language use in linguistic structure (semantic functions, lexical choices) between and within texts.

Data analysis procedures. While following an inductive approach, we were guided by topic of language ideology, language attitudes and MT status which are essential to understand current language practices in Singapore. The theoretical position informing our research assumes that MT status and function are illustrative of the causes for the decline of MT proficiency, thus providing contextualisation for understanding the language shift phenomenon. 
Based on the level of analysis, we compared the contents of the two documents to map topics/themes that appeared in both documents through the titles and focuses of different chapters. As we processed the texts chapter by chapter, we paid particular attention to topics related to the declining MT proficiency, linguistic environment, MT function and curriculum contents. These topics were then grouped together, based on their orientational intertextual relations to fit into the common theme. We identified the following common themes: policy statement about bilingual education, the language environment in Singapore, the purpose and goals of MT learning, and the instructional guiding principles. Table 1 shows the themes and their sub-thematic orientational topics.

Table 1: Themes and orientational topics

\begin{tabular}{|c|c|}
\hline Common Themes & Orientational topics \\
\hline Policy statement & $\begin{array}{l}\text { - Bilingualism as cornerstone of education } \\
\text { - Status of English: common language } \\
\text { - Status of MTs: transmission of Asian heritage } \\
\text { and values } \\
\text { - Language ideology: EL offers globalised } \\
\text { economic advantages, and MT cultural \& } \\
\text { localised economic benefits. }\end{array}$ \\
\hline $\begin{array}{l}\text { Changing linguistic } \\
\text { environment }\end{array}$ & $\begin{array}{l}\text { - } \\
\text { - Negalish as a dominant language in homes } \\
\text { speaking background towards learning MTs } \\
\text { - Varied level of MT proficiency students } \\
\text { - Doing well academically in MT is the incentive } \\
\text { for learning MT }\end{array}$ \\
\hline $\begin{array}{l}\text { Purpose and goals of MT } \\
\text { learning }\end{array}$ & $\begin{array}{l}\text { - Develop proficient language users } \\
\text { - Use MT in real-life situations } \\
\text { - Making MT a living language } \\
\text { - Strengthening communication skills }\end{array}$ \\
\hline Instructional guiding principles & $\begin{array}{l}\text { - Rescope curriculum to create time for interactive } \\
\text { language use } \\
\text { - Organise cultural camps } \\
\text { - } \quad \text { Creating } \\
\text { - Engage parents and community centres to } \\
\text { support MT learning } \\
\text { - Strengthening Pre-service and in-service training }\end{array}$ \\
\hline
\end{tabular}


In what follows, we present our findings and analysis of the documents, based on the three levels of analysis. We first present those themes that are explicitly consistent as they are construed between the two policy documents on the same grounds through matching chapter titles and contents. Following that, we discuss the ideological underpinnings of theses broad themes through concrete texts. Linking these texts to the socio-political decisions made over the past decades, we are able to contextualise the discursive construction of bilingual education in Singapore through orientational intertextual relations. The third step is look at the organisational relations, where we examine how semantic features, lexical choices and linguistic forms are used in the texts to depict bilingual education in Singapore. As such, the intertextual relations of orientational and organisational analysis can facilitate our understanding of what kinds of meanings are made and what kinds of meanings are not made, thus allowing us to locate implicit ideologies that may be conflicting or inconsistent between and within the two policy texts.

\section{Findings}

Our examination of the documents shows that although there are matching chapter themes, there are subtle inconsistencies, almost unnoticeable. Table 2 presents the consistent themes and inconsistent ideologies within and between the two policies.

Table 2: The consistent themes and inconsistent ideologies

\begin{tabular}{|c|c|c|}
\hline Common Themes & Consistencies & $\begin{array}{l}\text { Inconsistent Ideological } \\
\text { Orientations }\end{array}$ \\
\hline Policy statement & $\begin{array}{l}\text { - } \begin{array}{l}\text { Bilingualism as cornerstone of } \\
\text { education }\end{array} \\
\text { - Status of English: common } \\
\text { language } \\
\text { - Status of MTs: transmission of } \\
\text { Asian heritage and values }\end{array}$ & $\begin{array}{l}\text { Not all four official } \\
\text { languages are given equal } \\
\text { status }\end{array}$ \\
\hline
\end{tabular}




\begin{tabular}{|c|c|c|}
\hline $\begin{array}{l}\text { Changing linguistic } \\
\text { environment }\end{array}$ & 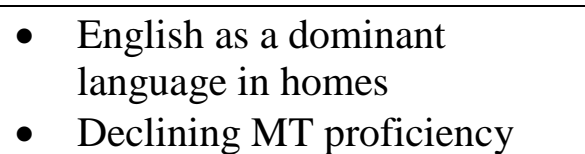 & $\begin{array}{ll}\text { - } & \text { Status planning does not } \\
\text { support MT development }\end{array}$ \\
\hline $\begin{array}{l}\text { Purpose and goals of } \\
\text { MT learning }\end{array}$ & $\begin{array}{ll}\text { - } & \text { Use MT in real-life situations } \\
\text { - } & \text { Making MT a living language } \\
\text { - } & \text { Strengthening communication } \\
& \text { skills }\end{array}$ & 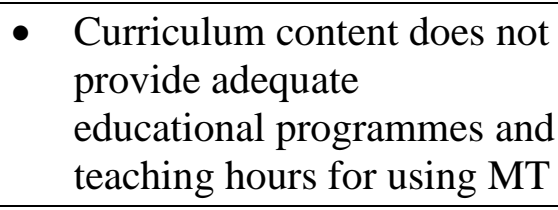 \\
\hline $\begin{array}{l}\text { Instructional guiding } \\
\text { principles }\end{array}$ & $\begin{array}{l}\text { - Rescope curriculum to create } \\
\text { time for interactive language } \\
\text { use } \\
\text { - Engage parents and } \\
\text { community centres to support } \\
\text { MT learning } \\
\text { - Creating conducive } \\
\text { environment for MT use and } \\
\text { learning }\end{array}$ & $\begin{array}{l}\text { - Oracy is given less emphasis } \\
\text { - Insufficient MT curriculum } \\
\text { time and input }\end{array}$ \\
\hline
\end{tabular}

\section{Policy Statement}

The explicit ideological position on bilingualism in Singapore is stressed consistently in the first chapter of both documents. As an opening statement in Chapter 1, Bilingualism as cornerstone is set as a crucial point for developing the rest of the policy documents. In the Report, the policy statement describes the importance of the bilingual policy this way,

Bilingual education in English (EL) and the Mother Tongue Languages (MTLs) remains imperative for Singapore. It is a cornerstone of Singapore's education system. EL, as the common language of instruction, enables all our students to plug into a globalised world. Economically it has built an environment conducive for international business here...

The learning of MTL has provided a link to their heritage and Asian roots for the various ethnic groups. (The Report, 2010, p.10)

In a similar vein, the Framework presents the policy as follows:

The bilingual policy is a cornerstone of Singapore's education system. It requires all students to study the English language (EL) and their mother tongue language (MTL). As a result, EL has become the common language of communication across the ethnic groups. The bilingual policy also promotes the study of MTLs as it plays an important part in affirming a sense of cultural identity among Singaporeans, ensuring the transmission of values from generation to generation. (The Framework, 2013, p.19) 
From the orientational level of intertextual analysis, we are informed that both documents have a common underlying ideology with regard to the roles English and MTLs play in the country's bilingual prospect. In the Report, English language (EL) is established as "the common language of instruction" that provides economic advantages for Singapore. While the role of English for economic gains is not mentioned in the Framework, it is recognised as the "common language of communication across the ethnic groups". At the level of operational analysis, the noun phrase 'common language' is chosen in both documents, albeit followed by different complements, so that the two documents arrive at different meanings. When put together, EL functions not only as the language of instruction in educational contexts but also as the lingua franca across the ethnic communities.

With regard to MTs, both documents clearly indicate that MTs are repositories of tradition and culture. This orientational positioning is conveyed by the operational sequences of the paragraphs. EL is given the first order to foreground the bilingual policy whereas the role of MTL is placed after that of the EL. In terms of lexical choice on the operational level, 'enable' (used in the Framework for EL) is a positive verb, much stronger than simply to 'provide a link' used for MTL. The ideological orientation towards EL and MTL is further compartmentalised and given different functions and roles in the documents. With English as the language of economic success in a 'globalised world' and MTL the language of cultural values and business for 'immediate region', language status is thus confirmed.

While there are further consistencies between the two documents, most of them tend to be related to the policy statement, emphasising cultural connections and associations for MT development. Inconsistencies, however, are between the official language status and the status planning activities (curriculum hours and language of instruction) to which we will turn our 
attention in the subsequent sections. Given the limited space in this paper, we cannot examine all the sub-thematic orientational topics. In what follows, we select a few overlapping orientational topics for further elaboration.

\section{Changing Linguistic Environment}

Another consistency in the documents is the government's deep concerns about MT language shift against the omnipresence of the English language. The documents list several facts that provide descriptive statistics of the MT language use in home domains. Describing the changing home language environment in Singapore, the Report establishes the context of change as:

The long-term trend of English becoming a dominant language used in homes is shown by time series data collected from parents of incoming Primary I (PI) students over the past twenty years. This rising trend is seen across all communities, albeit not to the same degree. Among ethnic Chinese students, the proportion of students with English as their most frequently used language at home rose from $28 \%$ in 1991 to 59\% in 2010. Among Indians, the corresponding figures are 49\% in 1991 and 58\% in 2010. For Malays, the rise was from $13 \%$ to $37 \%$ over the same period. (The Report, 2010, p. 29)

Framing the changing linguistic environment as a result of long-term development of English use in homes, the statistics reveal some alarming increase of language shift. While acknowledging that this rising trend can present inadequate language exposure for developing bilingual Singaporeans, the documents provide little contextualisation for understanding the trend. Instead of linking the trend with language status planning activities and official political ideology, the documents indicate that home language use is the main cause of MT decline, indirectly placing the responsibility of language shift on parents. This implicit inconsistency between MT decline and official language ideology is conveyed in the Report this way:

Home language was found to influence students' attitudes and proficiency in MTL: when compared with students from MTL-speaking or bilingual homes, fewer students from ELspeaking homes were found to like learning MTL. This suggested that teaching methods would need to be different for students from different home language backgrounds (The Report, 2010, p. 31). 
By using 'home language' as the subject in a passive voice of the first sentence, reader's attention is focusing on what wrong 'home language' has done. The object complement, "students' attitudes and proficiency in MTL", as influenced by 'home language', establishes the orientational context of the text. By taking the action of 'influence', 'home language' now has become the official culprit. Seeking support for this claim, a follow-up sentence is immediately added after the colon, (:), providing a reasonable explanation "when compared with students from MTL-speaking or bilingual homes, fewer students from EL-speaking homes were found to like learning MTL”. Without elaborating on how many students are from EL-speaking homes and why fewer children are motivated to learn MTL, the subject immediately shifts to suggesting that different pedagogical methods should be employed for teaching children from different home language backgrounds.

This orientation of home language causing language shift has long been studied in the field of language maintenance. Fishman (2001), for instance, in his eminent model of intergenerational language transmission, points out that the family is a critical domain for language maintenance and shift. Such a shift, however, is never a simple, domestic, and private affair. Scholars (Blommaert, 2005; Spolsky, 2009) have argued that language practices in private domains often are influenced by “language users' evaluative perceptions and conceptions of language and language use, based on the perceived value, power and utility of a language" (Curdt-Christiansen, 2014b, p. 2). In the context of Singapore, such evaluative stances are directly related to the language policy and the status of different languages leading to changes in home language use. To contextualise such evaluative stances towards different languages, three interrelated ideological issues are at play: status planning policy (working language in public), language-in-education planning, and the dichotomised view of EL and MTL. 
With regard to status planning, although the bilingual policy gives equal official status to English and the three MTs (Mandarin, Malay and Tamil), English has been given a premier position. In addition to its role as a neutral language for facilitating the establishment of a nonconflictual and harmonious nation, English is also used as working language in government administration, law, commerce, science, technology, and communication between different ethnic communities (Dixon, 2005). Such a strong status promotion policy of English has inevitably influenced people's attitudes towards MT and English, resulting in a change in language behaviours.

Secondly, as part of the status planning policy, the implementation of the language-ineducation policy, which promotes English as the language of instruction for all content subjects across all levels, adds a critical element to the changing language behaviours of Singaporeans. Baldauf (2005, p. 961) has succinctly pointed out that "language-in-education planning, through school, can become the sole language change agent".

Thirdly, one of the major goals of MT learning is to develop awareness and nurture children's appreciation of the local ethnic culture. The Framework specifically points out that,

Learning MTL enables our students to understand and develop their unique identity through a deeper appreciation of culture, tradition, literature and history. This is a critical base to preserve the transmission of cultural values and traditions associated with each MTL in our society (The Framework, 2013, p.13).

Indeed, language is an important vehicle for transmitting cultural values and traditions, but the separation of the functions of English and MTs can arguably generate very different attitudes towards these languages. While having a high level of proficiency in English can ensure access to a good school, placement into higher education and a good career with high income, the same cannot be said about a high level of proficiency in MT. The dichotomised view of English as having instrumental value and mother tongues as having cultural functions may create a tension 
between English and MT leading to unequal forms of 'social capital' in the linguistic market and placement in different social strata. May (2006) argues that the institutionalised linguistic compartmental ideology not only cannot stabilise the diglossic linguistic environment, it actually helps perpetuate the economic inequalities and widens the gap between the 'haves' and the 'have-nots'. In such a case, he continues to point out that the only 'rational' choice that seems to exist is to shift to languages with wider communication values in the long run.

The above mentioned three interrelated issues are fundamental in understanding the changes in home language practice and the attitudes towards MTL of children and their parents. Recognising the evolving linguistic environment and changing teaching methods to cater for students from different home language backgrounds may not rectify people's attitudes towards MT. Policies need to be consistent with regard to status planning activities that promote MTs which leads to our next discussion of inconsistencies between the declining MT proficiency and the goals of MT learning.

\section{Purpose and Goals of MT Learning}

In line with the language ideology of the bilingual policy statement, the documents stress:

[The] key purpose of MTL education would be to strengthen the communication skills of our younger generation, to cultivate cultural awareness and appreciation of their roots, and to enable young Singaporeans to connect with similar language communities across Asia and the world. (The Report, 2010, p. 36).

The underlying message is clear: in addition to its cultural function, MT should be a living language which students can use in real life situations. The ideology is further expanded in the Report, mobilising "the wider community to create environments in and beyond schools that are conducive to MTL learning and use. In this way, we can make MTL directly relevant to students - a living language and not just an examinable subject" (p. 37). 
While these broad objectives make sense, making MT a living language needs to be understood in relation to Singapore's language-in-education policy and the exam-oriented educational system. Although both MTs and English are constructed as official languages, in reality as well as in the policy of Primary Education, English is learned as a first language in primary school and MT a second language (MOE, 2013, p.5). This status planning policy has naturally limited the quality and quantity contact with MT. Teaching MT as a second language subject 30-40 minutes a day will inevitably have an effect on the use of MT as "a living language".

The inconsistency between the objectives and the official language-in-education policy can present further difficulties when promoting the functionality of MT beyond school, taking into consideration the exam-driven education culture. As stated in the Report (p. 31), a large survey of P6 students indicates that "doing well in the subject" is the incentive for them to learn MT. This indirectly reveals that students' interest in MT is driven by exam results, not by their interest in using the language for real life situations. In other words, achieving the objectives and increasing the use of MT would need consistent measures in instructional guidelines and curriculum planning.

\section{Instructional Guiding Principles}

\section{Building Oracy}

While both the Report and the Framework recognise that building communication skills is one of the most important objectives, they are not consistent with regard to building oracy skills. The Report views oracy as "the natural foundation for language learning" (p. 42) and treats it as integral parts of the MT curriculum, from which reading and writing can be built up. It provides specific guiding pedagogical principles as the following: 
There should be more systematic teaching of oral vocabulary and sentence structures to develop students' foundational language skills, taking into consideration their different starting points. Explicit instruction will be delivered in 'small doses' embedded within meaningful contexts and interspersed with engaging activities to avoid becoming repetitive drills' (The Report, 2010, p. 42).

The orientation and rationale for building up strong oracy skills is in alignment with the wider range of language practices and linguistic abilities of students in Singaporean homes. Given that more than 50\% P1 (Chinese and Indian) students use predominantly EL at home, the Report recognises the role of oracy plays in real life settings and for authentic communications. The Report further confirms that

Reading and writing activities will be built up primarily from the students' oral/listening activities so that they could learn the skills based on their oracy foundation. The same set of oral vocabulary and sentence structures learnt in oracy lessons will be reinforced and this will further aid their learning (The Report, 2010, p. 45).

As evidenced by this instructional guideline, oracy is regarded as the essential foundation for building up reading and writing skills. Specifically, in consideration of children with unequal MT proficiency and different use of English language at home, the Report further explicates that "for beginning learners and those who need more support in MTL learning, the teaching approach will be to first build the oracy foundation before learning reading and writing" (p. 42).

Despite the repeated emphasis in the Report on "systematic teaching of oral vocabulary and sentence structures", providing "explicit instruction" and "engaging activities" to enhance oracy skills, the Framework does not give due emphasis on oracy. Listening and speaking, rather, are indiscriminately listed as two of the four foundational linguistic skills. As one of the learnings goals, the Framework envisions that "children who have developed foundational language and literacy skills are able to communicate with people confidently" (2013, p. 29). In this transient visionary statement, foundational language and literacy skills are paralleled as an attribute to children. Unambiguously, literacy skills in this text and context are self-explanatory, 
referring to reading and writing skills. Foundational language skills, however, can be understood differently depending on the context - as speaking skills with basic vocabularies, and as prerequisite literacy skills, such as phonological awareness, concept of print, phonics and frequency words. The latter is often used in educational contexts. The lexical choice of "foundational language" seems to avoid the use of "oracy", thus directing reader's attention to "literacy".

This ideological orientation is a recurring concept throughout the document. For instance, "recognise words and read with assistance" is one of the major goals for developing children's MT, where they are encouraged to:

recognise simple words and phrases presented in the picture books. Children gain confidence from being able to read a simple picture book and this motivates them to learn more about the language (The Framework, 2013, p. 31).

The word "confidence" (or in its related form "confidently") seems to be closely linked with literacy ability as evidenced in "children gain confidence from being able to read" and "children who ...literary skills are able to communicate with people confidently". Oracy, on the other hand, has not been given the limelight. Goh (2002), for example, has observed that oracy as a practical fact "frequently occurs in class" but "is less frequently taught' (Goh, 2002, p.1).

The overt and repeated ideological conviction that favours literacy skills has its root in the educational system in Singapore. As we discussed in the earlier section, Singapore's educational system is meritocratic with emphasis on academic performance. As such, various high-stakes examinations set up challenging requirements for students to gain entry into different levels of education. As a consequence, educational attainment and success in school are perceived and measured by various tests and assessments and their results (Ang, 2006; CurdtChristiansen, 2010). The system of rigorous streaming on all levels has encouraged concerned 
parents to seek if not the best possible quality then the most efficient kind of education for their children. The kindergartens and preschools are pressured to favour curricula that focus on high test scores, and parents are pressured to choose preschools that emphasise formal literacy skills and preparation for primary schools. Sharpe (2002) noted that in their anxiety for their children to survive in Singapore's educational system, parents expect kindergartens to prepare their children to meet the demands of the exam-oriented schooling. In doing so, they demand preschools to prepare their children to do the work of primary school children so that upon entry to primary 1, their children are able to read and write (Ang, 2006; Lim-Ratnam, 2013). LimRatnam (2013, p. 420) noted that such expectations reflect the "society intent for preschool education focuses more on promoting academic outcomes with the objective of pre-emptying the work of the next level of schooling, rather than the holistic development of the child".

\section{Creating an Environment Conducive to MT Usage and Learning}

Another noticeable inconsistency is in the government's ambitious plan to "organise the learning environment" (the Framework, 2013, p. 47) and for "creating an environment conducive to MTL usage and learning" (the Report, 2010, p. 68). This educational ambition is expressed as follows:

To create an environment conducive for MTL learning, schools should have structured time and programmes that encourage students to use MTL and appreciate Chinese, Malay or Tamil culture. Doing so will enhance the learning experience for students and inspire their interest in MTL.

It is evident that the government is making conscious efforts to change the language behaviour of the younger generation by changing their attitudes towards MTs. The efforts are conveyed through strong suggestive verbs such as 'encourage', 'appreciate', 'enhance' and 'inspire'. These suggestive actions are subordinate to "structured time and programmes", thus conditioned by schools' decision on implementing relevant curriculum contents. 
While the guiding principles are making sensible meaning, the actual MT programme in schools has not reflected the desired curriculum goals. An effective curriculum with sufficient linguistic input for developing two languages has not yet been successfully implemented.

Currently, most preschools aim to connect with the primary school curricula, so they mimic primary school curricula to establish a strong foundation in children to develop their literacy and academic prowess. For most preschools, the medium of instruction is English, with only $20-25 \%$ contact time allocated to the teaching and learning of MT (Dixon, 2010). This does not qualify as being a strong bilingual programme as children in some situations are not taught MT as a L1. This discrepancy between top-down policy plan and the practical realisation was also found in Curdt-Christiansen's (2014b) study of primary schools regarding the allocation of curriculum time in Chinese language. This limited language contact and inadequate input have consequences for early bilingual education.

Aware that children in Singapore have insufficient linguistic exposure to MT, the Report continues to suggest that

Partnership with the media and other stakeholders will also help create platforms and opportunities for exposure to the MTLs. Together, schools, parents and community partners can play key roles in providing students with opportunities to be immersed in an environment conducive to the learning of MTL (the Report, 2010, p. 68).

While "partnership" with communities and parents is an ideal educational philosophy, to immerse students "in an environment conducive to the learning of MTL" is questionable. As we recall from the policy statements presented earlier, there are conflicting ideology and discrepant information between the Report and the Framework. In the Report, the policy statement asserts that English is "the common language of instruction". In the Framework, the policy states that "EL has become the common language of communication across the ethnic groups". 
Acknowledging English as the language of instruction in schools and the lingua franca across communities suggests that English has become more dominant as it is used not only in homes, but has penetrated workplaces, markets, schools and streets. This indicates undoubtedly that MT has a reduced social function despite the government's repeated ideological emphasis on its cultural values and Asian affiliation. The likelihood that an environment conducive for learning MT will be created is not high when the educational role as well as the social and economic power of the English language in Singapore continues to grow, thus inevitably shaping people's attitudes towards MT.

\section{Conclusion}

In this article, we have examined two government policies - Nurturing Early Learners: Framework for MTLs (A Curriculum for Kindergartens in Singapore) and Nurturing Active Learners and Proficient Users: Mother Tong Languages Review Committee Report. In order to understand the current bilingual educational challenges and concerns for young children, we have attempted to locate the consistencies and inconsistencies that define the implementation of bilingual programmes in Singaporean preschools. We have thus identified some of the factors that influence language shift in Singapore and the language environment for bilingual education in preschools. Constructing relations between texts and contexts will facilitate our understanding of what kinds of meanings are made and what kinds of meanings are not made, and how they index the ideological positions of the government.

Admitting that our examination does not cover all factors affecting early bilingual programmes, we have nevertheless addressed some of the more critical issues by paying special attention to the inconsistencies between and within the two policy documents. 
One of the major inconsistencies lies in the goals for MT learning and the recognition of the evolving linguistic environment. Both policies stress the importance of developing cultural awareness and appreciating local ethnic cultures. This emphasis has been repeatedly communicated in public discourse and political rhetoric over the past decades. However, the 'cultural persuasion' has not been observably effective, and the linguistic environment has not been in favour of the development of MTs. The attitudes of parents and children towards MTs are still ambiguous leading to further decline of MT competence. This is evidenced by the increase of children using dominantly English when they enter school, up from 28\% in 1991 to 59\% in 2010 for Chinese students (MOE, 2011). In order to change parental attitudes towards MT and increase the use of MT in home domains, policy goals and implementation procedures must be congruent. Currently, the status planning for MT focuses more on image promotion, highlighting the cultural values of MT, less on prestigious promotion to make it a functioning language. Hence, there is a need for cohesive policy positions to promote MTs which involves both attitudinal changes and language behavioural changes.

With regard to the learning goals in the two documents, an emphasis should be given to the alignment of the communicative teaching approach, recommended in the Report, with the needs of the various learners. The inconsistency we identified with oracy, however, does not reflect the learning goals in developing children's communicative language skills. This may inevitably lead to teachers' continued ignorance of oracy, given the exam oriented educational system that emphasizes literacy skills and academic proficiency.

While the significance of the evolving Singaporean linguistic environment has been repeatedly emphasised, the bilingual education programme is largely based on teaching two monolingual models. Institutional guidance and support for schools and teachers to understand 
how bilinguals acquire and process two or more languages is highly needed. This includes providing theoretical knowledge about the different types of bilingual models, and how different models can best maximise the learning opportunities.

Bilingual models, such as immersion, partial immersion and dual language programmes, should be included in teaching education programmes, so that all teachers (English and MT teachers) can benefit from the training. For example, what pedagogical approaches are effective for emergent bilinguals? What types of classroom activities should they organise for dual language classrooms? Teachers as well as parents often bring their own 'lay theories' about the nature of language use and language teaching into their classroom; these 'lay beliefs' can be challenging to tackle when implementing new pedagogical approaches and teaching methods (Hüttner, Dalton-Puffer and Smit, 2013).

One area that we consider noteworthy but have limited space to explore is teachers' training programme. While both documents highlight the need to cater to learners of varied language backgrounds and emphasise the challenging teaching environment in which teachers find themselves, the Framework provide little guidance on how to take into consideration "children's interests, needs and abilities when planning the MTL curriculum and activities" (Framework, 2013, p. 40). As the requirement for diploma attainment and kindergarten teacher training was only implemented in 2008 (MOE press, 2011), the Framework needs to provide detailed guidelines in every aspect.

Our analysis of the polices shows that in order to achieve effective bilingual education for young learners, policy objectives should be well-defined, instructional guidelines and principles should be in alignment with objectives, and teacher training programmes should be continuously updated to meet the changing culture and evolving characteristics of the students. 
In conclusion, policy decision and curriculum planning should be not only cohesive, but also consistent with regard to the goals and ideological positions. Out analysis shows that inconsistencies between and within policies can cause confusion among teachers, students and parents, thus contributing to conflicting attitudes towards bilingual education and mother tongue learning. Such conflict will not only hinder the development of a "strong foundation for MTL learning" but also impede the smooth transition from kindergarten to primary school.

\section{References}

Ang, L.L.Y. (2006). Steering debate and initiating dialogue: A review of the Singapore preschool curriculum. Contemporary Issues in Early Childhood, 7(3), 203-212.

Baker, C. (1992). Attitudes and language. Clevedon, UK: Multilingual Matters.

Baker, C. (2011). Foundations of bilingual education and bilingualism $5^{\text {th }}$ ed. Bristol: Multilingual Matters.

Baldauf, R.B. Jr. (2005). Language planning and policy research: an overview. In E. Hinkel (Ed.), Handbook of research in second language teaching and learning (pp. 957-970). New Jersey and London: Lawrence Erlbaum.

Blommaert, J. (2005). Discourse: A critical introduction. Cambridge: Cambridge University Press.

Buyl, A. \& Housen, A. (2014). Factors, processes and outcomes of early immersion education in the Francophone Community in Belgium. International Journal of Bilingual Education and Bilingualism, 17(2), 178-196.

Cormier, M., Bourque, J., \& Jolicoeur, M. (2014). (Re)-introduction to French: four education models to revitalise an endangered group in Eastern Canada. International Journal of Bilingual Education and Bilingualism, 17(2), 160-177.

Curdt-Christiansen, X.L. (2009). Visible and invisible language planning: Ideological factor in the family language policy of Chinese immigrant families in Quebec. Language Policy, 8(4), 351-375.

Curdt-Christiansen, X.L. (2010). Competing priorities: Singapore teachers' perspectives on critical literacy. International Journal of Educational Research, 49(6), 184-194.

Curdt-Christiansen, X. L (2014a). Family language policy: Is learning Chinese at odds with leaning English in Singapore. In X.L. Curdt-Christiansen \& A. Hancock (Eds.); Learning Chinese in Diasporic communities: many pathways to being Chinese (pp.35-58). John Benjamins.

Curdt-Christiansen, X.L. (2014b). Planning for Development or Decline? Education Policy for Chinese Language in Singapore. Critical Inquiry in Language Studies, 11(1), 1-26. 
Curdt-Christiansen, X.L. (2016). Conflicting language ideologies and contradictory language practices in Singaporean bilingual families. International Journal of Multilingual and Multicultural Development.

Curdt-Christiansen, X.L. \& Silver, R.E. (2013). New Wine into Old Skins: The Enactment of Literacy Policy in Singapore. Language and Education, 27(3), 246-260. DOI:10.1080/09500782.2012.704046

Dendrinnos, B. (2014). The politics of instructional materials for English of young learners. In X.L. Curdt-Christiansen \& C. Weninger (Eds.); Language, ideologies and education: The politics of textbooks in language education (pp. 29-49). London and New York: Routledge.

Dixon, L.Q. (2005). Bilingual education policy in Singapore: an analysis of its sociohistorical roots and current academic outcomes. International Journal of Bilingual Education and Bilingualism, 8(1), 25-47.

Dixon, L. Q. (2010). The importance of phonological awareness for the development of early English reading skills among bilingual Singaporean kindergartners. International Journal of Bilingual Education and Bilingualism, 13, 723-738.

Eton House. (n.d.) Eton House Language programmes. Retrieved 15 May, 2015 from: http://www.etonhouse.com.sg/language-programs.html

Fairclough, N. (2001). Language and power. Harlow, England: Longman.

Fairclough, N. (2010). Critical discourse analysis: The critical study of language. Harlow, England: Longman.

Fishman, J. A. (2001). Language maintenance, language shift, and reversing. In T.K. Bhatia and W. Ritchie (eds), The Handbook of Bilingualism (pp. 406-436). Oxford, UK: Blackwell.

Framework (2013). Nurturing early learners: A curriculum for kindergartens in Singapore. A framework for mother tongue languages. Singapore: Singapore Ministry of Education.

Gee, J. (2005). An introduction to discourse analysis: Theory and method. New York: Routledge.

Goh, C. C. M. (2002). Teaching listening in the language classroom. SEAMEO Regional Language Centre.

Hickey, T.M. \& de Mejia, A. (2014). Immersion education in the early years: a special issue. International Journal of Bilingual Education and Bilingualism, 17(2), 131-143.

Hickey, T.M. (2001). Mixing beginners and native speakers in minority language immersion: Who is immersing whom? Canadian Modern Language Review, 57(3), 443-474.

Hickey, T.M. (2013). Early bilingual education. In C. Chapelle (ed.), Encyclopedia of Applied Linguistics (pp. 1816-1822). Oxford: Blackwell.

Hickey, T.M. Lewis, G. \& Baker, C. (2014). How deep is your immersion? Policy and practice in Welsh-medium preschools with children from different language backgrounds. International Journal of Bilingual Education and Bilingualism, 17(2), 215-234.

Hüttner, J.C., Dalton-Puffer, and Smith, U. (2013). The power of beliefs: Lay theories and their influence on the implementation of CLIL programmes. International Journal of Bilingual Education and Bilingualism, 16(3), 267-284. 
King, K. A. (2000). Language ideologies and heritage language education. International Journal of Bilingual Education and Bilingualism, 3(3), 167-184.

Lee Sien Loong (2010). Nurturing active learners and proficient users. Mother Tongue Languages Review Committee Report. Singapore: Singapore Ministry of Education.

Lemke, J.L. (1992). Intertextuality and educational research. Linguistics and Education, 4, $257-$ 267.

Lenneberg. E.H. (1967). Biological foundations of language. New York: Wiley.

Li, W., Saravanan, V. \& Ng, J. (1997). Language shift in the Teochew community in Singapore: A family domain analysis. Journal of Multilingual and Multicultural Development, 18(5), 364-384.

Lim-Ratnam, C. (2013). Tensions in defining quality preschool education: The Singapore context. Educational Review, 56(4), 416-431.

Lindholm-Leary, K. (2014) Bilingual and biliteracy skills in young Spanish-speaking low-SES children: impact of instructional language and primary language proficiency. International Journal of Bilingual Education and Bilingualism, 17(2), 144-159, DOI:10.1080/13670050.2013.866625

Marinova-Todd, S. H., Marshall, D. B., \& Snow, C. E. (2000).Three misconceptions about age and L2 learning. TESOL Quarterly, 34, 9-34.

May, S. (2006). Language policy and minority right. In T. Ricento (Ed.), An introduction to language policy: theory and method (pp. 255-272). Oxford, UK: Blackwell Publishing.

May, S. (2013). Indigenous immersion education: International developments. Journal of Immersion and Content-Based Language Education, 1(1), 34-69.

McCarty T.L. (2011)(ed.), In Ethnography and Language Policy. London and New York: Routledge.

MOE (Ministry of Education) (2008). The Pre-School Qualification Accreditation Framework. Retrieved 15, May 2015 from: http://www.moe.gov.sg/education/preschool/files/pqacaccreditation-standards.pdf.

MOE (Ministry of Education) (2011). Preschool Portal, 2011. Retrieved 15, May 2015 from: Http://www.moe.gov.sg/initiatives/compularoty-education.

MOE (Ministry of Education) (2012). Education in Singapore. Retrieved 6 June 2013, from http://www.moe.gov.sg/about/files/moe-corporate-brochure.pdf

Moyer, A. (1999). Ultimate attainment in L2 phonology: The critical factors of age, motivation and instruction. Studies in Second Language Acquisition, 21, 81-108.

Muñoz, C. \& Singleton, D. (2011). A critical review of age-related research on L2 ultimate attainment. Language Teaching, 44(1), 1-35.

Murugayyan, Y.K. (2011). Early literacy apprenticeship: A comparative study of two K2 classes in Singapore. Unpublished MA thesis. Nanyang Technological University, Institute of Education, Singapore.

Nikolov, M. (2010). Colloquium - Early learning of English: Learners, teachers, and discourses. Language Teaching, 43(1), 105-108. 
ÓhIfearnáin, T. (2013). Family language policy, first language Irish speaker attitudes and community-based response to language shift. Journal of Multilingual and Multicultural Development, 34(4), 348-365.

Pakir, A. (2008). Bilingual education in Singapore. In J. Cummins and N. Hornberger (eds), Encyclopedia of Language and Education: Bilingual Education (pp.191-204). Amsterdam: Springer.

Rogers, R. (2011). Becoming discourse analyst: constructing meanings and identities. Critical Inquiries in Language Studies, 8(1), 74-104. DOI: 10.1080/15427587.2011.545768

Report (2011). Nurturing active learners and proficient users. Mother Tongue Languages Review Committee Report. Singapore: Singapore Ministry of Education.

Santello, M. (2015). Bilingual Idiosyncratic Dimensions of Language Attitudes. International Journal of Bilingual Education and Bilingualism 18: 1-25.

Sharpe, P. (2002). School days in Singapore: Young children's experiences and opportunities during a typical school day. Childhood Education, 79(1), 9-14.

Vaish, V. (2007). Bilingualism without diglossia: The Indian community in Singapore. International Journal of Bilingual Education and Bilingualism, 10(2), 171-186.

Wodak, R., \& Meyer, M. (2009). Critical discourse analysis: History, agenda, theory and methodology. In R. Wodak \& M. Meyer (Eds.), Methods of critical discourse analysis (pp. 1-34). Thousand Oaks, CA: Sage.

Woolard, K. A. (1998). Introduction: Language ideology as a field of inquiry. In B.B. Schieffelin, K. A. Woolard \& P.V. Kroskrity (Eds.), Language ideologies: Practice and theory (pp. 347). New York and Oxford: Oxford University Press.

Zhao, S. \& Liu, Y. (2008). Home language shift and its implications for language planning in Singapore: from the perspective of prestige planning. The Asia Pacific-Education Researcher, 16(2), 111-126.

Zhao, S. H. \& Liu, Y. B. (2010). Chinese education in Singapore: The constraints of bilingual policy from perspective of prestige planning. Language Problems and Language Planning, $34.3,236-258$.

Zhao, S.H \& Zhang, D. (2014). Conflicting Goals of Language-in-Education Planning in Singapore: Chinese Character (汉字 Hanzi) Education as a Case. In X.L. CurdtChristiansen \& A. Hancock (Eds.); Learning Chinese in Diasporic communities: many pathways to being Chinese (pp.35-58). John Benjamins. 